\title{
Na potência do envolvimento: palavras de intelectuais indígenas
}

\author{
In the potency of simplicity: development in the word of \\ indigenous intellectuals
}

\author{
Josemar de Campos Maciel ${ }^{1}$ \\ Levi Marques Pereira² \\ Yan Leite Chaparro ${ }^{3}$
}

DOI: http://dx.doi.org/10.20435/tellus.vi44.744

Resumo: O trabalho que segue apresenta variações de uma concepção do desenvolvimento inspirada no esforço de diálogo com o pensamento indígena. Nossa metodologia é hermenêutica, e desdobra-se em dois momentos. O primeiro é uma revisão sintética da relação entre a colonização, o desenvolvimento e a sobrevivência da vocalidade indígena. Para este momento, usamos a literatura científica do campo historiográfico e filosófico. O segundo momento é uma apresentação em categorias tipológicas de algumas visões indígenas do que viria a ser desenvolvimento, construídas a partir da leitura de textos produzidos por intelectuais indígenas. O resultado esperado do trabalho é contribuir com o adensamento do respeito pela contribuição dos indígenas para pensar uma versão saudável, sustentável, justa e nativa do desenvolvimento do Brasil, que denominamos como "envolvimento", adotando a formulação expressa por um indígena kaiowá, autor de um dos textos no presente dossiê.

Palavras-chave: estudos críticos do desenvolvimento; desconstrução; sociedade; filosofia intercultural.

Abstract: The text that follows presents variations of a conception of development inspired by the dialogue with indigenous thought. Our methodology is hermeneutic, and it unfolds in two moments. The first is a synthetic review of the relationship between colonization, development and survival of indigenous vocalities. For this moment, we deploy scientific literature from the historiographic and philosophical field. The second moment that

\footnotetext{
${ }^{1}$ Universidade Católica Dom Bosco (UCDB), Campo Grande, Mato Grosso do Sul, Brasil.

${ }^{2}$ Universidade Federal da Grande Dourados (UFGD), Dourados, Mato Grosso do Sul, Brasil.

${ }^{3}$ Universidade Católica Dom Bosco (UCDB), Campo Grande, Mato Grosso do Sul, Brasil; Universidade Federal da Grande Dourados (UFGD), Dourados, Mato Grosso do Sul, Brasil.
} 
follows, is a presentation in typological categories of some indigenous views of development, built from experience and from some texts produced by indigenous intellectuals. The expected result of the work is to contribute to the increase in respect towards the contribution of the indigenous people to think of a healthy, sustainable, fair and native version of the development of Brazil, which we call "involvement".

Keywords: critical studies of development; deconstruction; society; intercultural philosophy.

\section{INTRODUÇÃO}

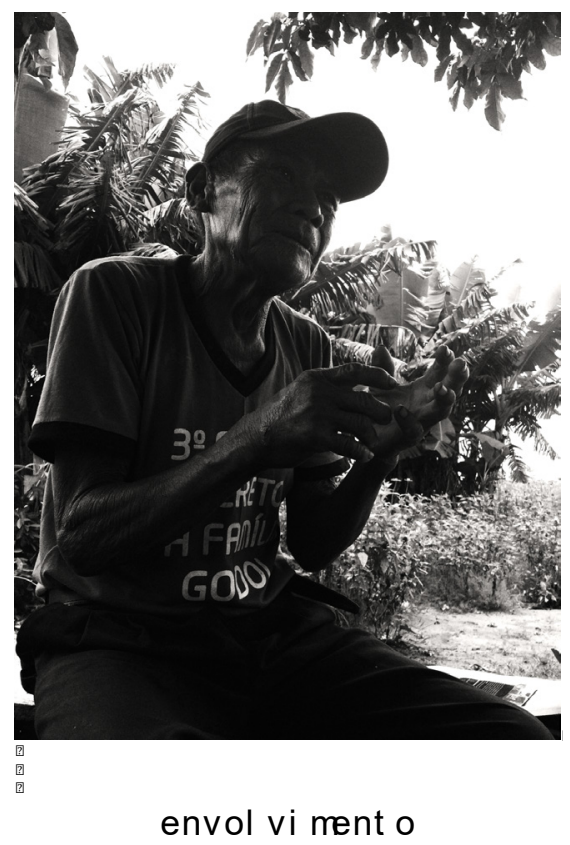

Fonte: Yan Leite Chaparro, 2018. Cartaz

"Envolvimento".

O pressuposto fundamental deste trabalho é que a ciência brasileira tem uma oportunidade importante de pôr-se à escuta da concepção indígena do desenvolvimento, pois ela é de uma fecundidade impressionante. Lado a lado com outras concepções, também desmerecidas pelas ao longo da nossa história, marcada pela dependência, subalternização e colonialidade, pode somar forças para produzir um grande enriquecimento. Mas para chegar a esse ponto, sem pretender propor uma leitura completa da história do desenvolvimento, para o 
que remetemos a bons estudos atuais (e.g. PEET; HARTWICK, 2015), precisaremos resumidamente antepor uma apresentação da tensão que o caminho de construção da modernidade/colonialidade nos legou, até o presente momento (MIGNOLO, 2012). Nossa atenção é à sua forma lógica, fundamentada por reflexões historiográficas e filosóficas. Após essa apresentação, percorreremos algumas concepções de intelectuais indígenas que podem acenar para um caminho de pensamento e de prática que vai além do desenvolvimento.

\section{ACELERAÇÃo}

Existe evidência historiográfica que suporta a tese de que a história do desenvolvimento pode ser resumida a partir de duas categorias tipológicas de grande espectro. Trata-se do binômio aceleração e (tentativas de) silenciamento (ROSA, 2013). O movimento de aceleração é flanqueado por outro movimento, de sequestro de parcelas do ambiente (SHIVA, 2016), originalmente de interesse público, para produzir uma aceleração da dinâmica social e produtiva, ordenada a partir de interesses privados - pessoais ou institucionais, ligados a centros de articulação e reticularização de poder. Esse movimento de sequestro gera bolsões de aceleração, rodeados por áreas que, paradoxalmente, se desaceleram para sustentá-la. É desnecessário dizer que esse movimento, assim descrito, está sendo pensado não a partir da Europa, nem de seus ideais, mas a partir daquela área geográfica, rica e que cada vez se torna mais evidente também como área intelectual, chamada de "Sul Global". Inicialmente designada a partir do modelo aceleracionista, como se necessitasse de locomotivas para alcançar o movimento dos países centrais (PRASHAD, 2012), esta região vem fazendo ouvir cada vez mais a sua voz, que ressalta a riqueza do seu patrimônio que, para além da aceleração e do acúmulo financeiro, mostra-se como riqueza e diversidade (AMIN, 2019).

Desde os primórdios da marcha do desenvolvimento, que podemos situar a partir das grandes navegações que aceleram a Europa desde o século 14, com o início das grandes viagens e projetos de navegação ultramarina, em busca de matérias-primas para renovar os centros de poder nas escaramuças das cortes europeias (SIQUEIRA, 2009), foi acontecendo um movimento de rearranjo de toda a dinâmica geopolítica, nos escombros da Idade Média, e de toda a dinâmica produtiva do planeta (AMIN, 2011). É bem documentado o surgimento do 
Mercantilismo, que substitui o modo de produção feudal na Europa. Ainda, é bem clara na literatura a relação entre a Europa e os continentes que vão sendo alinhados em uma equação na qual os Viajantes/Conquistadores identificam o que eram riquezas a seus olhos, como metais, especiarias, mão de obra, etc., e aos poucos vão dispondo de tudo, como se fosse sua propriedade (FORBES, 2008). Ao mesmo tempo, vai surgindo o delineamento do que se chamará Modernidade, com seus Estados nacionais, suas línguas e literaturas. Paralelamente, grande parte do movimento intelectual, seja científico, filosófico e especialmente, historiográfico, destinou-se a legitimar esta forma de relação. Os Viajantes/colonizadores seriam denominados Pioneiros, e os destinatários, teoricamente, deveriam sentir-se muito felizes por fornecer sua mão de obra, no caso da África e de algumas regiões da América Latina, além da Ásia, e ver o seu ambiente ser aos poucos utilizado convertido em "Recursos" (RIST, 2001; 2014; FANON, 1961 [1968]).

A palavra é importante, porque mostra claramente que, na modernidade, o mundo passa a ser visto a partir de uma perspectiva de expansão, domínio, relações de poder assimétricas, e exploração do ambiente com vistas a convertê-lo em subsídio para um novo sistema econômico-financeiro que mais tarde seria chamado de capitalismo. De fato, a palavra "desenvolvimento", juntamente com as suas irmãs gêmeas "progresso" e "evolução", possuem uma longa história de desgaste, transformando-se cada vez mais em máscaras sem muita densidade por detrás, em slogans ou Buzzwords (RIST, 2007). Ao redor desses ideais, criaram-se diversas camadas de retórica para justificar projetos que, na prática, produzem enormes impactos. Em nome de slogans utópicos, justificar-se-iam mortes de biomas, pilhas de cadáveres, perda de consistência social e de nacionalidades. No Brasil, um dos países que nasce nas franjas do avanço colonizador, isso produz uma dupla perversidade, enquanto o desenvolvimento trata populações nativas como se fossem estrangeiras nas suas próprias terras, e ainda as tenta arregimentar para a implementação dos projetos que lhes são, efetivamente, estranhos.

A este ponto, muito mais que criticar regimes econômicos, convém apontar o tensionamento que surge, ao longo do movimento de estabelecimento da modernidade colonizadora. Por um lado, há países e comunidades inteiras que se constroem a partir da ideia de prospecção, exploração e acumulação para benefício próprio, de outros povos e ambientes. Isso, obviamente, com a condescendência de autoridades, e com a cooptação e uso de líderes locais que, aos poucos, vão 
sentindo-se coparticipantes na distribuição das benesses oriundas da inserção de seus países nessa dinâmica mais geral ou globalizada. Do outro lado, aos poucos vai se mostrando necessário silenciar as visões próprias e dissidentes, dessas localidades. Assim, no processo de colonização, surge uma literatura de propaganda religiosa ou científica - que desacredita iniciativas, cosmologias, conhecimentos e práticas dos povos que aos poucos vão sendo atingidos e explorados. As narrativas dominantes, sejam de natureza política, religiosa ou científica, se esforçam por convencer os povos subalternizados da ausência de perspectivas de futuro viável fora da noção apresentada como desenvolvimento. Por outro lado, desde cedo haverá denúncias e resistências importantes (MARTINEZ, 2012), e com o tempo a historiografia anota a erosão que vai afetando e causando prejuízos a uma imensa malha de civilizações, com seus usos, línguas e costumes, além dos cadáveres que se amontoam (ESCOBAR, 1995; BATALLA, 1982; DOREL, 2006). A evidência dessa percepção por parte de governos e cientistas leva algumas organizações de caráter internacional, como a Organização das Nações Unidas (ONU) e a Organização Internacional do Trabalho (OIT), a proporem formas de proteção para as populações locais, sob pena de elas serem atropeladas e terem sua existência ameaçada pelo desenvolvimento a partir de uma lógica unilateral.

É possível anotar que, entre especialistas, há um debate interessante perguntando se o que aconteceu ao longo da história dos encontros coloniais pode ser melhor denominado como genocídio, etnocídio, ou mesmo a combinação dos dois processos. Um dos autores que documenta o debate, Dorel (2006), observa que a ideia de genocídio é mais emocional, e ressalta o enorme número de indivíduos que foram mortos ao longo dos anos, na verdade dos séculos, de encontro moderno/colonial. Acentua, noutros termos, o aspecto etnodemográfico. Por outro lado, ele anota que existe uma linha historiográfica que enfatiza a ideia do etnocídio, ou seja, sem negar o enorme número de mortes, pode se olhar também qualitativamente para todo esse tempo de encontros, como um tempo em que populações mais aparelhadas tecnologicamente, tornaram mais vulneráveis as populações mais hospitaleiras.

Sem reconhecer, desde o início, que estavam sob ataque, e sem saber que seriam inundadas por cosmologias materialistas e pragmáticas, que visavam a exploração do seu ambiente sem ligações com qualquer ideia de solidariedade ou de direitos humanos, muitas populações indígenas foram exterminadas sem se 
dar conta da gravidade do que estava acontecendo. A noção de etnocídio aponta para duas tentativas de extinção. A primeira, seria a extinção dos indivíduos. A segunda, seria a destruição do seu modo de existir, comprometendo o patrimônio material e espiritual, o que equivaleria a um esforço de legitimação de todo o processo de ocupação e de posse do ambiente, já convertido devidamente em recurso mediante processos de retórica, para ser convertido por sua vez em objeto, ou em amontoados de objetos dotados de valor de troca.

Com o estabelecimento da modernidade, o binômio aceleração e silenciamento vai ficando cada vez mais claro, até que se estabelece uma narrativa que é basicamente centrada na articulação entre o progresso, o conhecimento, e as relações de poder, já devidamente legitimadas. Alguns países traçam a agenda da aceleração e a executam, extraindo a matéria-prima para isso de todo o resto do planeta. Pelo elevado grau de assimetria nas relações estabelecidas, isso vai sendo denominado como imperialismo, e acontece partindo da Europa e sendo assimilado nos Estados unidos, que repetem a sua forma de atuar em relação aos países que Ihes fornecem matéria-prima para o seu desenvolvimento, em especial no período posterior a segunda Guerra Mundial. Essa relação geopolítica é uma das causas do desgaste no uso das fontes de todo o planeta, e se preserva, até o século XXI, agudizada no trânsito entre as linguagens, e na crescente sofisticação dos métodos discursivos de justificação (PATNAIK; PATNAIK, 2016). Estamos dizendo aqui "fontes" (de vida, de riqueza, de mão de obra) para reservar a palavra "recursos" ao seu uso técnico, do ambiente transformado em natureza, ou seja, em bem consumível.

Estudos mais atuais mostram que a relação entre o norte que se desenvolve e o sul global que lhe fornece matéria-prima, não se modificou estruturalmente, mas ganhou novos atores e novas linguagens a partir do fim do século 19 e início do século 20, até o século 21. Em outras palavras, apesar da retórica da Integração Mundial, continua presente e ativo um tensionamento herdado da época colonial. Importa a posse da agenda e a capacidade, primeiro comercial, depois bélica e, em seguida, suavemente bélica, se aceitamos a tese do soft power - ou seja, a capacidade de diminuir a força do outro em termos de argumentação, representação diplomática e capacidade de dispor das próprias riquezas. E a agenda da marcha do planeta, teimosamente denominada como agenda de desenvolvimento, continua em mãos daqueles primeiros países que foram mais 
agressivos e que foram capazes de se posicionar em relação às disputas de poder internas à Europa e, em seguida, desde a Segunda Guerra Mundial, dependentes dos Estados Unidos da América do Norte. Agora o movimento inclui outros países, de outros continentes, que lutam para sair da condição subalterna, mas são também vítimas de golpes de estado e de intervenções de organizações internacionais que desarticulam na raiz as suas possíveis lideranças (JERÓNIMO; MONTEIRO, 2018).

A noção de desenvolvimento que estamos discutindo aqui é tão potente, e possui raízes tão importantes, que transcende e é capaz de estruturar regimes políticos. A ex-União Soviética e atualmente a China, lugares em que foram implantados regimes totalitários comunistas, também não fogem dessa relação com suas populações internas subalternizadas e com os países com os quais desenvolvem relações colonialistas, mesmo quando assumem a feição de livre comércio. No caso da China, avidez na expansão e conquista de matérias primas e commodities agrícolas e minerais, além da abertura de mercados para seus produtos, surpreende até os países de tradição produtiva consolidada, como no caso dos EUA, ameaçando sua hegemonia e traçando relevos agressivos para os perfis de futuras competições e negociações.

Temos assim, um ideal, que até hoje é muito influente sobre o planeta: os países mais desenvolvidos devem continuar o seu desenvolvimento, que envolve o estabelecimento de uma indústria de conversão do ambiente em produtos para serem consumidos, enquanto países não desenvolvidos, subdesenvolvidos, ou classificados a partir do eufemismo "países em desenvolvimento", ficam reduzidos à posição de satélites fornecedores de matéria-prima e mão de obra desregulamentada para sustentar os esforços de aceleração e consumo, e maior aceleração e ainda maior consumo.

As visões de mundo e as formas de conhecimento nativas, desses povos, vão sendo deslegitimadas ou mesmo silenciadas, a partir de estratégias muito sofisticadas, mas também muito bem documentadas.

\section{TENTATIVAS MALOGRADAS DE SILENCIAMENTO}

Uma estratégia mais antiga era o aprendizado das línguas nativas, aliado ao ensino das línguas do centro, para sustentar as relações coloniais. Aos 
poucos, disciplinas derivadas ou disciplinas que trabalham com a linguagem, da linguística à etnologia, passando pela história e antropologia, foram tomando conhecimento de problemas críticos para essa forma de se relacionar com as populações locais, e as referidas iniciativas de aprendizagem. Para o controle das denominadas "populações locais", surgiu a administração indireta, se instrumentalizando das organizações políticas das próprias comunidades, como aconteceu na África, mas também com populações indígenas no Brasil, com a criação de reservas com posto do Serviço de Proteção aos Índios (SPI/FUNAI) (ALMEIDA; CAVALCANTE, 2019). Nem sempre o faziam apenas para conseguir encontrar ouro, pedras preciosas ou escravos. Nascia a antropologia mais crítica, como a conhecemos hoje. O processo é bem documentado na literatura (SEVERO, 2016; MATA, 2019; MARIANI, 2004).

Há estratégias, no entanto, que tiveram grande sorte, sobretudo por terem sido incorporadas a uma narrativa de senso comum.

A primeira delas é o dispositivo de narrar as histórias das comunidades indígenas no passado ou, em expressão filosófica, tratar os povos tradicionais e as comunidades afrodiaspóricas como povos "sem história", mal-entendidos e caracterizados desde fora, com olhares desconfiados que veem apenas aquilo que não possuem, comparativamente. "Os povos com escrita revelam, com toda nobreza, o território da história; os selvagens serão objeto dos etnólogos" (NGOENHA, 2018, p. 33). Existe uma maciça produção bibliográfica que representa, nas escolas, as populações indígenas como nativos que receberam alegremente os portugueses, depois inesperadamente, começaram a fazer guerra e a comer alguns lusitanos assados. Logo, a pareceram os pioneiros heróicos que domesticaram algumas dessas populações, mas infelizmente elas teriam se extinguido. Essa narrativa é muito comum em regiões do país nas quais a atividade industrial se estabeleceu com mais força. Um exemplo é São Paulo, e outro o Rio de Janeiro. De fato, também nas regiões mais dedicadas à atividade agrícola, e atingidas pela revolução tecnológica da agricultura de massa que se inicia por volta de 1970. As populações indígenas também são colocadas no passado, através de outras estratégias discursivas. Uma delas, é a estratégia assimilacionista, segundo a qual os indígenas que permanecem vivos não seriam indígenas puros-sangue. Seriam apenas oportunistas, interessados em beneficiar-se de políticas de assistência, divulgadas pelo Estado (SOUZA LIMA, 1995). 
Uma variante dessa estratégia, assumida por cientistas, muitas vezes com boas intenções, é a vitimização das populações nativas. Segundo alguns trabalhos muito conhecidos e importantes, as populações indígenas teriam sido sujeitas de um massacre, seriam vítimas do desenvolvimento, o que transformaria o nosso país em pretensa cópia de sociedades europeias transladadas, mal acomodadas em um ambiente tropical. Esse pessimismo está registrado no clássico, no mais uma grande obra, os chamados tristes trópicos de Lévi-Strauss (1955). De fato, no andar dos anos, os próprios indígenas têm reagido às narrativas que desmerecem a potência da sua voz, aparecendo cada vez mais como interessados em defender o seu lugar, sua cultura e sua história na relação com a sociedade não indígena, trazendo contribuições efetivas, pensadas a partir da negociação entre o seu modo tradicional de vida e as inovações das quais, aos poucos vão se apropriando, mas a seu modo, e no seu ritmo.

A última estratégia que registramos, que tenta desqualificar a voz indígena no que se refere ao desenvolvimento, assume a forma de uma falácia, clara e afrontosa. Consiste em desqualificar como interlocutores, ensinando e divulgando a ideia segundo a qual as populações indígenas seriam eminentemente atrasadas, em relação às concepções de desenvolvimento (LOUREIRO, 2010).

Há várias evidências que não se encaixam e questionam essa narrativa. A mais notória, e que nos interessa imediatamente, é o aparecimento na esfera pública da voz dos povos cujos espaços foram sendo ocupados pelos movimentos expansionistas. Inesperadamente, essas vozes não silenciaram mas, pelo contrário, erguem-se de diversas formas.

A primeira forma, é um movimento de protesto, assimilado a partir da interlocução com missionários e cientistas mais sensíveis e mais críticos, e também mediante atividades que foram sendo úteis para o estado brasileiro e que mostraram a força das Nações Indígenas nativas (BANIWA, 2012). Nota-se por exemplo a presença deles em atividades comerciais, na recuperação de diversos recursos que foram sendo extintos ou seriamente atingidos pelas marchas de desenvolvimento, além da sua inserção inteligente e criativa nas sociedades nacionais nas quais se encontram inseridos.

A segunda forma, é a admirável utilização da escola, como instrumento para a produção da própria cultura e formas de vida, contrariando as intenções 
de governo de colocá-la a serviço da assimilação dessas populações à lógica desenvolvimentista. De fato, a escola tem sido, ao longo do tempo, uma grande ferramenta de socialização e formação intelectual para as populações. As comunidades indígenas se apropriaram dela, de diversas formas, e não sem diversos conflitos. Nesse sentido, destacam-se num movimento de rediscussão da própria herança cultural, patrimônio, folclore, questões políticas, e modos de vida. O Brasil tem visto, nas últimas décadas, uma forte atividade indígena de apropriação cultural inclusive formando indígenas como bacharéis e até doutores em antropologia, direito, e diversas outras especialidades, que Ihes parecem interessantes (LOPES DA SILVA; GRUPIONI, 1995).

Enfim, embora a escolarização dos indígenas aponte para processos complexos, que comportam contradições e ambiguidades, fica evidente que muitas vezes eles se apropriam da escola para produzir transformações em seu próprio sistema social, orientadas para o fortalecimento do seu modo de ser e para a busca de autonomia frente às relações institucionais nas quais estão imbricados com o Estado e com a sociedade nacional. Isto parece ocorrer com mais evidência quando acessam os programas de pós-graduação e a possibilidade de se formarem enquanto pesquisadores, não apenas como reprodutores de conhecimento disciplinares, como se pode verificar na entrevista concedida por Dominique Gallois, publicada nesse dossiê.

\section{SEMENTES DE UMA TIPOLOGIA}

Aqui, queremos enfatizar alguns traços do pensamento indígena que tem potencial para contribuir com o redimensionamento das discussões sobre desenvolvimento. Esta proposta é realmente modesta, pois estamos selecionando algumas amostras que nos são muito visíveis, de um amplo movimento de intelectualidade que recobre praticamente todo o Sul Global (DIRLIK, 2007). O nosso intento, não é oferecer uma filosofia indígena completa e acabada, mas chamar a atenção para a dignidade da reflexão que está sendo produzida no Brasil, e que pode abrir novas agendas, apontando para novos caminhos de reflexão sobre o desenvolvimento (BERGAMASCHI, 2014; PERES, 2017).

Uma primeira observação, praticamente transcendental, sobre o pensamento indígena em relação ao desenvolvimento é a sua recusa a aceitar a dualidade 
homem-natureza, ou sujeito-objeto (KRENAK, 2019). O texto de Eliel Benites e Levi Pereira, incluído nesse dossiê aponta para várias dessas características a partir da etnografia kaiowá. As populações indígenas e suas lideranças intelectuais, são especialistas em sobrevivência na relação com interlocutores muito agressivos, como foram os viajantes ibéricos, até a atual situação de exacerbação dos modelos capitalistas no mundo contemporâneo. Além disso, são especialistas em negociar com guardiões dos diversos espaços de existência, o que redunda numa relação mais equilibrada com o ambiente. Desenvolveram estratégias para prover as suas necessidades nutricionais sem devastar nem desertificar os seus biomas nativos, por considerá-los providos de vida, linguagem, sentimentos, intencionalidades, desejos e potências.

Talvez o segredo dessa maestria nasça da sua imersão no ambiente e na vida comunitária, que se articulam em uma grande diversidade de cosmologias, em que articula sua percepção que tende a ser sofisticada, mas não seccionada, sobre a realidade (VIVEIROS DE CASTRO, 2015). São especialistas em preservar o ambiente, provendo as suas necessidades nutricionais sem devastar nem desertificar os seus biomas nativos, por considerá-los povoados por diversos tipos de vidas e significados. Pouco ainda se fez na grande academia para levar a sério, a propósito, a força da presença indígena na inspiração dos chamados "pioneiros" dos movimentos ambientalista, de defesa dos animais não-humanos, e da discussão sobre a sustentabilidade. Assim que a academia, ou agências públicas capturam os temas, os indígenas vão sendo postos em uma posição de novo silenciamento, o que não se pode mais aceitar, justamente pela presença indígena ir aumentando nesses meios.

Defendemos a posição que a discussão deve superar o seu contexto etnocêntrico, indo muito além de debates públicos acerca de ideias restritas de qualidade de vida, índices de desenvolvimento humano, sustentabilidade, mundo 4.0, e outras criações ocidentais que intensificam a perspectiva de aceleração, e produzem de fato muito mais impacto sobre os sistemas de vida já bastante fragilizados (LÉVI-STRAUSS, 1976; BRASÃO, 2014; ALMEIDA, 2019).

Assim, para o nosso ensaio de tipologia do desenvolvimento que tem se destacado nos últimos anos, no Brasil, seguimos alguns momentos, a saber, a relação com a territorialidade; a visão da agricultura; a visão da violência dos pioneiros e, finalmente, uma proposição para além do desenvolvimento. 


\section{SOFISTICAÇÃO E DELICADEZA NA RELAÇÃO COM A TERRITORIALIDADE}

É de conhecimento dos cientistas a urgência e a dimensão do problema fundiário brasileiro. Ele atravessa a história do Brasil desde a descoberta. A instituição da República, não estruturou suficientemente a relação entre o sistema produtivo e o sistema fundiário, e as relações entre as pessoas interessadas em produzir, trabalhar ou viver, a partir dos recursos ambientais ( leia-se, a partir da relação com o mundo "rural") são constantemente conflitivas, com deficiências de regulação, e ainda marcadas por disputas de poder amparadas em grande violência e em mobilização do aparato estatal e comunicacional para defender interesses particulares (OLIVEIRA, 2001; SANTOS, 2009). Exemplo disso, para ficarmos apenas em um exemplo, é o levantamento das terras indígenas já regulamentadas mas não homologadas pelo estado do Mato Grosso do Sul, realizado em 2014 (ELOY AMADO, 2013). Na verdade, o país já fala de internet 5.0, mas ainda tem dificuldade para entender o que é uma terra indígena (CAVALCANTE, 2016).

Para além da injustiça, da omissão do Estado e das dificuldades da discussão em campo jurídico, os indígenas têm se articulado de forma diversificada e criativa, em agremiações de coletivos de povos, como no caso da Articulação dos Povos Indígenas do Brasil (APIB) e em importantes personalidades de grande impacto na mídia e nos meios jurídicos e acadêmicos, como Ailton Krenak, Luiz Eloy Terena, Davi Yanomami, Tonico Benites, Eliel Benites e muitos outros, como mostram estudos acadêmicos e articulações institucionais (SILVA, 2018; ALCÂNTARA; TINÔCO; MAIA, 2018).

Os problemas de demarcação dos territórios indígenas no Brasil obscurecem grandes contribuições dessas populações para o pensamento dos processos de territorialização. Se o Brasil é um país de dimensões continentais, ele também é um repositório de muitas práticas e sistemas de propriedade, e também de moradia. Em toda a extensão territorial nacional existem populações que vivem em distintos meios bióticos, como a mata atlântica, floresta amazônica, planície pantaneira, cerrado, etc, ou que transitam entre eles, com maior ou menor mobilidade, de acordo com as referências de produção de sua territorialidade específica e formas de acesso aos recursos necessários à reprodução física e cultural de seus coletivos.

Ressaltamos, por exemplo, no centro-oeste, a riqueza da experiência sedentária Xavante, da experiência mobilidade por um amplo território e da prática de 
agricultura dos do Povo bo'e (Bororo). E ainda a experiência reticulada de territorialidade da etnia guató, que se destaca como grandes navegadores sobretudo na região do Pantanal, contribuindo para a produção de aterros de origem antrópica, de fundamental importância para estabelecimento de moradias, mesmo no período de enchentes e para o cultivo de espécies agrícolas, sem perder de vista a integração dos diversos territórios, realizada a partir de leves e sofisticadas canoas que singram toda a estrutura hídrica da região.

Para além da regulamentação jurídica do simples direito a existir, mantendo suas práticas, o Brasil ainda carece de uma reflexão sistemática, em grande escala, sobre as possibilidades e as riquezas de explorar simbolicamente esses múltiplos regimes de territorialidade.

Na prática, uma das vertentes mais importantes para o estabelecimento da participação mais ativa e propositiva das populações indígenas nas estruturas institucionais do país, nos últimos anos, tem sido a luta pela reivindicação do seu direito às suas terras. Essa reivindicação é fundamental para os estudos críticos do desenvolvimento, pois é uma peça em um quebra-cabeças que envolve alguns focos fundamentais de interesses: as populações indígenas, as populações afrodescendentes e afrodiaspóricas, agricultores não mecanizados e tradicionais e, do outro lado, com grandes recursos e pesados investimentos, os interesses geopolíticos e os partidários da "revolução verde" (TEDESCO; SEMINOTTI; ROCHA; 2018; BINKOWSKI, 2018; BRAGATO; BIGOLIN NETO, 2017).

Não é um embate de fácil solução, mas é óbvio que a voz indígena, sendo originária, e tendo muita experiência na construção e conservação do território desde muito tempo (grande parte da academia os conhece apenas desde 1500, se muito), deveria ter uma voz bem mais ouvida, para que o modelo de desenvolvimento brasileiro pudesse espelhar as matizes da sua população. Por ora, no entanto, o embate travado no país é o de preservar as conquistas da geração que se ergueu por volta dos anos 1980, e que se cristalizou ao redor da liderança de Raoni Metuktire e do veemente discurso de Ailton Krenak, organizado por Sérgio Cohn (2015), apoiados pelo melhor da ciência social brasileira. Não queremos esgotar o tema do conflito sobre as terras, mas ressaltar que não é feita ainda, em um país extremamente diverso e rico, uma exploração sustentada dos diversos regimes de territorialidade indígena, com suas práticas arquitetônicas e diversos tipos de soluções de relacionamento entre os povos. 


\section{UMA AGRICULTURA CONECTADA À DIMENSÃO COSMOLÓGICA E A OUTROS PLANOS DE EXISTÊNCIA}

A etnia Terena possui uma longa história de resistência, que se intensificou a partir do século XIX. A partir da guerra do Brasil contra o Paraguai, eles foram obrigados a se deslocar do próprio território, e colaborar com o exército brasileiro (SEBASTIÃO, 2016). Essa guerra, no século 19 considerada por historiadores a primeira "guerra total", antes da primeira grande guerra européia (CAPDEVILLA, 2010), afetou pesadamente a sua concepção do território, obrigando-os a negociar diversas práticas da sua forma de vida tradicional.

De fato, enfrentaram graves conflitos quando o Estado brasileiro promoveu, à guisa de ocupação e integração produtiva do território nacional, um forte rearranjo produtivo, incentivando a ocupação das terras ancestrais terena por agricultores, sobretudo no interior do Mato Grosso do Sul. Até esta data, permanecem conflitos territoriais, e os Terena articulam-se para reivindicar seus territórios e para regulamentar a sua posse, com destaque para o movimento da retomada, a partir de 1988 (VARGAS, 2011; PEREIRA, 2009; AZANHA, 2005).

Se essa situação é difícil, por outro lado a resistência dessa etnia mostrou seu grande potencial de resistência e de criatividade. Um projeto modelo, que está se enraizando pelo país, é o Projeto Gestão Ambiental e Territorial Indígena (Projeto GATI), que pensa e promove a prática de formas extremamente avançadas de atuação agrícola, conectadas ao conhecimento ancestral dessa população (MACIEL et al., 2019; SIQUEIRA JUNIOR, 2016). Na aldeia Lagoinha, por exemplo, a partir dessa base, articulou-se a associação Caianas, que é uma união de lideranças que planejam e acompanham a execução de diversas atividades para qualificar o modesto território nessa terra indígena (BENITES; SANT'ANA; ANTONIO; AGUILLAR; COSTA, 2016). Isso acontece num intercurso de sabedoria tradicional e necessidade. A terra, quando a comunidade retornou, encontrava-se bastante degradada, e teve que ser recuperada. O processo de recuperação seguiu o processo tradicional, que envolveu as orações dos rezadores; os conhecimentos dos professores, a alegria das crianças e mulheres, e envolve, entre outras atividades, a recuperação de nascentes, o plantio de espécies tradicionais, colecionando e adquirindo por via de troca sementes nativas. Leosmar Antônio reporta que, ao tomar posse da aldeia "Mãe Terra", na Terra Indígena Lagoinha, 
[...] o terreno estava muito degradado. Nós precisávamos urgentemente de um processo de restauração. Para nós, foi como se alguém tivesse afastado nossa mãe de nós, maltratando-a profundamente. Tivemos que cuidar dela novamente e, com o tempo, fomos capazes de regenerar parte dela. Este processo de restaurar e dar vida à terra, nossa mãe, significou ir vendo a mata crescendo novamente, permitindo que os animais retornassem para mais perto, voltando à nossa terra. É importante cuidar da floresta. É também uma forma de fornecer comida para as pessoas. Hoje estamos cultivando uma grande variedade de safras em um pequeno pedaço de terra. Estamos fazendo isso da maneira tradicional e não oferecendo sementes geneticamente manipuladas às comunidades locais, como está acontecendo dentro do sistema que promove as monoculturas. A maneira como estamos cultivando visa promover a autonomia das comunidades locais. É nosso entendimento que o Estado brasileiro não está favorecendo essa autonomia. Muitas variedades locais de espécies operam no risco de desaparecimento e buscamos restaurar a biodiversidade. A riqueza da nossa herança inclui 19 variedades de mandioca, 7 variedades de feijão, 7 variedades de batata-doce, cana-de-açúcar, banana, arroz. Essas variedades sustentam a soberania alimentar da nossa população. (MACIEL et al., 2019, p. 866).

Podemos afirmar, que para eles, de certa forma, a agricultura é uma atividade que se conecta profundamente a raízes muito importantes do sistema de vida. $\mathrm{Na}$ narrativa acima aparece, por exemplo, a conexão firme entre a relação com a ancestralidade, na menção da maternidade do ambiente. Ademais, diversos aspectos tradicionalmente seccionados nas experiências científicas sobre sustentabilidade agrícola, aparecem ali como conectados em um processo de restauração da própria casa, e de reconstrução das condições de segurança alimentar do próprio povo.

Este exemplo, entre outros existentes entre comunidades indígenas, ostenta com clareza a capacidade de articulação entre saberes tradicionais, novas tecnologias e improvisação criativa, gerando não apenas sustentabilidade, mas o enriquecimento da biodiversidade ( $c f$. também ANTONIO; SANT'ANA; MELO, 2016). O estado brasileiro faz bem, cada vez que se debruçar para ouvir o que estas lideranças têm a contar.

\section{UMA PSICOPATOLOGIA INDÍGENA DO DESENVOLVIMENTO}

Antropólogos como Arturo Escobar (1995) e Guillermo Bonfil Batalla (1982), evidenciam o desenvolvimento, na visão dos povos indígenas, como um encontro 
com um visitante agressivo, inóspito e violento. Sobre o movimento de resistência muito já se escreveu. Mas sobressai na literatura acerca do encontro entre essas populações e o mundo civilizado e tecnológico a obra "queda do céu", escrita pelo Pajé Yanomami Davi Kopenawa, em parceria com o antropólogo Bruce Albert (KOPENAWA; ALBERT, 2015).

Essa obra abre uma perspectiva que podemos denominar de psicopatologia nativa do desenvolvimento ocidental. Em diversos sugestivos capítulos, Davi kopenawa mostra que o ser humano possui uma conexão com o ambiente que envolve não apenas desejos superficiais e tecnologia de manipulação direta. Na visão do seu povo, o ser humano e o ambiente possuem uma relação de intrínseca e articulada dependência, entendida por analogia com um corpo unificado. Essa relação se resolve na escuta de diversos horizontes anímicos que guardam a floresta, o solo e os diversos modos de vida senciente: humanos, não humanos e mesmo não sencientes, todos possuem uma espécie de espírito, ou seja, possuem uma relação intrínseca a ponto de necessitarem vitalmente uns dos outros. Todos se comunicam, em diversas esferas e a partir de diversas linguagens, tendo a obrigação de respeitar-se para não quebrar a harmonia nem desarranjar as condições do sistema de vida. A quebra dessa harmonia é uma espécie de apagamento da luz ou perda de funções vitais, uma forma de adoecimento.

Ora, com a chegada do homem tecnológico, esse mundo se desarranja, porque o homem tecnológico não sabe ouvir. A sua vida é marcada pela visão, mas não uma visão panorâmica, nem aberta à percepção das dinâmicas do horizonte. Pelo contrário, a visão embriagada pela tecnologia e pelo espírito de guerra, quando entra na mata, possui focos muito claros e muito isolados: ela não consegue ver a mata. Apenas destina-se a identificar possibilidade de extração de madeira, que já não é vista como árvores, seres vivos, mas como material para fazer objetos. A possibilidade, ainda, de extração de metais e pedras consideradas preciosas, que isolados do solo produzem um esfriamento do corpo que é a floresta. Corpo indígena, por extensão. Essa forma de sentir os diversos movimentos como movimentos vivos produtores de relações, é afetada pela agressividade da técnica e do extrativismo pouco sofisticado de uma concepção de desenvolvimento baseada na conversão do ambiente em recurso para produzir acúmulo de valores abstratos, como nos ensina Gilbert Rist (2001; 2007; 2014). 
Kopenawa entende que o ser humano não indígena, aquele que perdeu o contato com suas raízes e com os espíritos da floresta, está doente. Sua doença é um apagamento dos olhos, que o torna incapaz de ver o que precisa ser visto, ou seja, as profundas relações entre as coisas. E é ainda, uma obstrução da escuta, pela qual ele não ouve mais, não consulta os antigos habitantes da floresta, e a depreda, produzindo apenas a destruição e inclusive pondo sob ameaça o seu próprio mundo. Esta leitura também possui documentação histórica, apesar da sua forma poética e mística. Ao mesmo tempo, assemelha-se à ideia da "Wetiko", doença que, segundo a comunidade Haudenosaunee, no Norte da América, transformava os brancos em uma espécie de zumbis, apagados, infelizes, violentos, muito afanados em destruir tudo o que se move e devorar. Uma espécie de canibais sem causa e sem rumo (FORBES, 2008).

Nosso Pajé não aponta uma saída fácil para essa situação. Ele é pajé, não economista. Ele não planeja o futuro com a técnica, mas possui o condão, o talento e a função social de ouvir as diversas potências, e pô-las para conversar, interagir entre si.

E a sua visão de xamã nos ensina que o homem, adoecido, começa a considerar a natureza - de resto, a "natureza" é mais uma invenção moderna - como sua inimiga, ou como matéria a ser transformada em outra coisa. Com isso, abre o flanco para um violento efeito de rebote sobre a própria espécie, sobre o planeta. A solução que pode ser divisada, a partir desta concepção do desenvolvimento como um céu que cai e se abate sobre todos os povos, é uma forma de autocrítica, e um reconhecimento dos méritos e da riqueza dos povos nativos.

\section{UMA NOVA CONCEPÇÃO: O ENVOLVIMENTO}

A quarta reflexão de intelectuais indígenas é a proposta de efetuar a transição de concepção de uma vida adequada. Ela vai do desenvolvimento ao envolvimento, e aparece em falas Guarani. A reflexão dos Guardiões das palavras.

A quarta concepção do desenvolvimento que queremos apresentar, parte da Mística Comunidade dos Guarani. Mais especificamente, do professor Eliel Benites, que propõe, em linha com a proposta também mística de Kopenawa, substituirmos a ideia de desenvolvimento por aquela, a ele muito cara, de envolvimento. Podemos dar-lhe a palavra por alguns momentos. 
A palavra desenvolvimento já é um problema, para nós não é desenvolver, mas sim envolver. Nossos conhecimentos, nossas vidas, passam por um envolvimento por tudo. Para a sociedade moderna é desenvolver economicamente, crescer com coisas. Mas, para nós é envolver. Começa aí a diferença, são como dois rios que seguem caminhos contrários, caminhos muito diferentes, um rio vai para um lado e outro rio vai para outro lado. A diferença já começa com a palavra, porque desenvolvimento é tirar o envolvimento, crescer sem sentido, desenvolvimento é como não se envolver com todos os elementos da vida. E para nós é diferente, para nós é se envolver com tudo que existe como vida, com cada elemento da vida, com a criança, com as plantas, com a água, com a casa, com tudo que é vida. Envolvimento, envolver que é sensível, que é espiritual, que é concreto. Então é por aí que começa a discussão, nessa diferença. Então é por aí que você precisa começar, que para nós é envolvimento. (CHAPARRO, 2019, p. 65, grifo nosso).

Alguns comentários podem ajudar a identificar a enorme potência desta forma mentis, aqui apenas recortada em uma parte de um encontro, que foi também uma entrevista. A fala de Eliel representa a visão de mundo guarani, em sua autoridade de jovem liderança e também de professor acreditado academicamente. Ela traz alguns recortes.

O primeiro recorte pode ser menos evidente, para um leitor desavisado. A maioria das pesquisas sobre o desenvolvimento desconsidera em parte os interesses do interlocutor, por conta do pesado investimento institucional sobre os programas e recursos. De fato, os programas não têm tempo, nem paciência, para interessar-se por sistemas originários (ou hibridizados) de vida, pois o foco normalmente é postado sobre experiências ou aspectos da vida que possam gerar grandes indicadores, a saber, emprego e renda.

No caso desta entrevista específica, porém, aconteceu o encontro da academia com os hábitos, costumes e ideias tradicionais Guarani. A própria dinâmica da conversa aconteceu em movimento, caminhando e longe de qualquer imposição de agenda ou de assunto. Por detrás dos pés e gravadores, estava em movimento todo um sistema de vida. Especificamente para esta entrevista, feita em caminho, em parceria e sem 100 perguntas estruturadas, para que a voz indígena pudesse se manifestar em suas próprias coordenadas.

Nesse extrato textual, aparece claramente como a visão ocidental do desenvolvimento é enviesada, a partir da fixação na aceleração de indicadores objetivos de bem-estar e de acúmulo de valores. 
Quando o guarani observa que "desenvolvimento é tirar o envolvimento, crescer sem sentido, desenvolvimento é como não se envolver com todos os elementos da vida", ele descreve com agudez o movimento denominado por Karl Polanyi (2001) como "a grande transformação", ou seja, a substituição que vai sendo realizada aos poucos, mas sem complacência, dos sistemas de vida e das trilhas de solidariedade, por instituições mais supostamente objetivas, que servem com clareza aos fins da agenda que está de posse de poucos, ou seja, a conversão do que é comum em privado; a conversão de sistemas de vida em sistemas de geração de lucro. A voz Guarani, ancestral, olha com ironia e diz que esse movimento é em parte, um crescimento sem sentido. Em boa teoria econômica, para citar apenas Nicholas Georgescu-Roegen (1995), desenvolver-se sem sentido equivale a não levar em consideração a lei básica de toda a Biologia, ou seja, o fato de que os sistemas da terra são finitos, e que o grande objetivo da marcha do desenvolvimento deveria ser o aumento da biodiversidade, a partir de políticas inteligentes, e de sistemas de vida fruíveis, mas nem por isso abusivos ou agressivos. O ocidente ainda não soube nem sequer esboçar um projeto nesse sentido. Por pura surdez aos povos originários.

Em poucas palavras, o foco da perspectiva para a qual os esforços de desenvolvimento podem convergir, por sua vez, ao menos nesta fala Guarani, é a superação do antropocentrismo por uma espécie ou variante mística do ecocentrismo. Sem renunciar à produção de tecnologia para prover as necessidade da(s) espécie(s), mas sem deixar de considerar o primeiro objetivo de todo o processo: produzir uma vida boa e condividi-la, no aqui e agora, com a participação de todos, humanos e não humanos (ACOSTA; MARTINEZ, 2011)

Trata-se de superar de uma vez por todas a ruidosa confusão entre desenvolvimento, que é um desabrochar de potencialidades, e uma convivência entre atores que estão adequados em suas funções mas também satisfeitos em seus desejos íntimos, e crescimento, ou melhor, tiremos-lhe a máscara retórica, acumulação de ativos financeiros, disfarçada como aumento de qualidade de vida (CORNWALL; EADE, 2010).

A visão indígena do desenvolvimento substitui um prefixo privativo por uma palavra que implica na produção sustentada de um ambiente no qual todos os povos, humanos e não-humanos, sencientes e não sencientes, encontram-se contemplados, e podem celebrar a festa da conexão profunda que existe entre os 
seres que se sustentam, alimentam mutuamente, e ordenam os seus esforços no sentido de mais encontro, de mais festa e de mais diversidade. Mas existir e produzir coletivos entre os Kaiowá e Guarani exige o domínio de conhecimentos e sabedoria para ter a capacidade de agregar os parentes, dando densidade e operacionalidade ao coletivo da parentela, unindo-os na defesa e proteção mútua. Exige também, o domínio de linguagens capazes de conectar os seres que habitam os distintos planos do cosmos e tornar seguro o caminhar-oguata, pelos distintos planos de existência. Parafraseando Guimarães Rosa, nesse mundo complexo e heterogêneo, viver se torna algo muito perigoso, onde os procedimentos do encantamento-ojepota e da negociação-ñemongueta, são atributos necessário ao caminhante por essa terra, no destino irrefutável de produzir o envolvimento.

\section{SÍNTESE}

Esse trabalho, que não se entende completo, quer marcar alguns rumos a partir dos quais temos pensado, e desejamos continuar pensando o desenvolvimento com força territorial, e com sensibilidade ao patrimônio, considerado a partir do ecocentrismo e da etnossensibilidade. Em poucas palavras, podemos apontar alguns traços do caminho que os pensadores mais críticos podem percorrer, em uma aliança com a escuta qualificada da intelectualidade indígena.

Antes de qualquer coisa, trata-se de proceder a uma recuperação da força da hospitalidade primordial com a qual os povos originários receberam - e continuam recebendo - os povos da inovação e da técnica. Trata-se de abrir espaço para todos, mas um espaço que não reduza os costumes e as culturas a uma matriz dominante.

Mais tematicamente: precisamos reafirmar a possibilidade de reaprender com as populações indígenas a simplificar a percepção dos ideais de vida, abrindo espaço para concepções mais sofisticadas, inclusivas e comunitárias da experiência do habitar e do pertencer. Desenvolver uma relação desalienada, ativa com o planeta, que não é um consumível, mas uma casa comum, entendendo melhor como funcionam as conexões entre seres, tais como nascentes que provêm água; sementes que fornecem alimento e oxigênio, a longo prazo. Em outras palavras, mais atenção ativa, diante das cadeias de vida. Aumentar a nossa escuta para entender a vizinhança como recurso de construção de uma civilização que celebra a vida, e que se celebra como construção de memória. 


\section{REFERÊNCIAS}

ACOSTA, Alberto; MARTINEZ, Esperanza (Org.). La naturaleza com derechos: de la filosofía a la política. Quito: Ediciones Abya-Yala, 2011.

ALCÂNTARA, Gustavo Kenner; TINÔCO, Lívia Nascimento; MAIA, Luciano Mariz (Org.). Índios, direitos originários e territorialidade. Brasília: ANPR, 2018.

ALMEIDA, Marco Antônio; CAVALCANTE, Thiago Leandro Vieira. Capitão: a aplicação da indirect rule nos povos Kaiowá e Guarani. Tellus, Campo Grande, n. 39, p. 39-60, maio/ ago. 2019.

ALMEIDA, Jozimar Paes. A extinção do arco-íris: ecologia e história. Rio de Janeiro: Centro Edelstein de Pesquisa Social, 2008.

AMIN, Samir. The long revolution of the global south: toward a new anti-imperialist international. New York: Monthly Review Press, 2019.

AMIN, Samir. Global History: a view from the south. Oxford: Pambazuka Press, 2011.

ANTONIO, Leosmar; SANT'ANA, Graziella Reis; MELO, Aislan Vieira (Org.). O curso agricultor agroflorestal na promoção da autonomia Terena: uma articulação entre Família GATI (Organização CAIANAS), Projeto GATI e IFMS/PRONATEC. Brasília: Projeto GATI/FUNAI, 2016.

AZANHA, Gilberto. As terras indígenas Terena no Mato Grosso do Sul. Revista de Estudos e Pesquisas, Brasília, v. 2, n. 1, p. 61-111, jul. 2005.

BANIWA, Gersem. A conquista da cidadania indígena e o fantasma da tutela no Brasil contemporâneo. In: RAMOS, Alcida Rita. Constituições nacionais e povos indígenas. Belo Horizonte: UFMG, 2012.

BATALLA, Guillermo Bonfil (Ed.). America Latina: etnodesarrollo, etnocidio. Costa Rica: Flacso, 1982.

BENITES, Eliel; SANT'ANA, Graziela Reis; ANTONIO, Leosmar; AGUILLAR, Renata; COSTA, Renata. A experiência do Projeto GATI em terras indígenas - Cachoeirinha, Jaguapiré, Lalima, Pirakuá, Sassoró, Taunay Ipegue. Brasília: IEB, 2016.

BERGAMASCHI, Maria Aparecida. Intelectuais indígenas, interculturalidade e educação. Tellus, Campo Grande, n. 26, p. 11-29, jan./jul. 2014. 
BINKOWSKI, Patrícia (Org.). Análise de conflitos e relações de poder em espaços rurais. Porto Alegre: UFRGS, 2018.

BRAGATO, Fernanda Frizzo; BIGOLIN NETO, Pedro. Conflitos territoriais indígenas no Brasil: entre risco e prevenção. Revista Direito e Práxis, Rio de Janeiro, v. 8, n. 1, p. 15695, mar. 2017.

BRASÃO, Heber Junio Pereira. O etnocentrismo como elemento constitutivo da cultura ocidental. Cadernos da Fucamp, Monte Carmelo, v. 13, n. 19, p. 62-72, 2014.

CAPDEVILLA, Luc. Una guerra total: Paraguay, 1864-1870. Buenos Aires: SB Editorial, 2010.

CAVALCANTE, Thiago Leandro Vieira. "Terra indígena": aspectos históricos da construção e aplicação de um conceito jurídico. História, Franca, v. 35, n. 75, 2016. Disponível em http://www.scielo.br/scielo.php?script=sci_arttext\&pid=S0101-90742016000100501\&ln $\mathrm{g}=\mathrm{pt} \& \mathrm{nrm}=\mathrm{iso}$.

CHAPARRO, Yan Leite. Este é nosso corpo, a terra: caminhos e palavras Avá Guarani/ Ñandeva de Porto Lindo (Jakarey) Yvy Katu para além do fim do mundo (Yvy péa ha'e ore rete: tapekuéra ha ñe'ẽnguéra Ava Guarani/Ñandéva Jakareypegua Yvy Katu amogotyove oparire ko ñapyrũha). 2019. Tese (Doutorado em Desenvolvimento Local) - Universidade Católica Dom Bosco, Campo Grande, MS, 2019.

COHN, Sérgio. (Org.). Encontros: Krenak Ailton. Rio de Janeiro: Azougue, 2015.

CORNWALL, Andrea; EADE, Deborah (Org.). Deconstructing development discourse: Buzzwords and fuzzwords. Oxford: Practical Action Publishing/Oxfam GB, 2010.

DIRLIK, Arif. Global South: predicament and promise. Indiana University Press, v. 1, n. 1, 2007, p. 12-23.

DOREL, Frederic. La thèse du "génocide indien": guerre de position entre science et mémoire. Amnis: 2006.

ELOY AMADO, Luiz Henrique. Pokéexa ûti: o território indígena como direito fundamental para o etnodesenvolvimento local. 2013. Dissertação (Mestrado em Desenvolvimento Local) - Universidade Católica Dom Bosco, Campo Grande, MS, 2013.

ESCOBAR, Arturo. Encountering development: the making and unmaking of the third world. Princeton: Princeton University Press, 1995.

FANON, Frantz. Les damnés de la terre. Paris: La Découverte, 1961 [1968]. 
FORBES, Jack D. Columbus and other cannibals: the wetiko disease of exploitation, imperialism and terrorism. New York: Seven Stories Press, 2008.

GEORGESCU-ROEGEN, Nicholas. La décroissance: entropie, écologie, économie. Paris: Éditions Sang de la Terre, 1995.

JERÓNIMO, Miguel Bandeira; MONTEIRO, José Pedro (Org.). Internationalism, imperialism and the formation of the contemporary world: the pasts of the present. Cambridge: Palgrave Macmillan, 2018.

KOPENAWA, Davi; ALBERT, Bruce. A queda do céu: palavras de um xamã Yanomami. São Paulo: Companhia das Letras, 2015.

KRENAK, Ailton. Ideias para adiar o fim do mundo. São Paulo: Editora Schwarcz, 2019. LÉVI-STRAUSS, Claude. Raça e história. In: LÉVI-STRAUSS, Claude. Antropologia Estrutural II. Rio de Janeiro: Tempo Brasileiro, 1976. p. 328-330.

LÉVI-STRAUSS, Claude. Tristes tropiques. Paris: Plon, 1955.

LOPES DA SILVA, Aracy; GRUPIONI, Luis Donizeti Benzi (Org.). A temática indígena na escola. Brasília: MEC/MARI/UNESCO, 1995.

LOUREIRO, Violeta Refkalefsky. Desenvolvimento, meio ambiente e direitos dos índios: da necessidade de um novo ethos jurídico. Revista direito GV, São Paulo, v. 6, n. 2, p. 503-26, 2010.

MACIEL, Josemar de Campos; SURIAN, Alessio; BRAHMLLARI, Estela; TARASCONI, Bibiane Ferreira; ANTONIO, Leosmar. Terena agriculture and life-system: a speech and beyond. Interações, Campo Grande, v. 20, n. 3, p. 861-77, 2019.

MARIANI, Bethania. Colonização linguística: línguas, política e religião no Brasil (séculos XVI a XVIII) e nos Estados Unidos da América (século XVIII). Campinas: Pontes, 2004.

MARTINEZ, Alejandro Rosillo. La tradición hispanoamericana de derechos humanos: la defensa de los pueblos indígenas en la obra y la praxis de Bartolomé de Las Casas, Alonso de la Veracruz y Vasco de Quiroga. Quito: Corte Constitucional del Ecuador, 2012.

MATA, Inocência Luciano dos Santos. Epistemologias do "colonial" e da descolonização linguística: uma reflexão a partir de África. Gragoatá, Niterói, v. 24, n. 48, p. 208-26, 2019.

MIGNOLO, Walter. Local histories/global designs: coloniality, subaltern knowledges, and border thinking. Princeton: Princeton University Press, 2012. 
NGOENHA, Severino Elias. Filosofia africana: das independências às liberdades. Maputo: Paulinas, 2018.

OLIVEIRA, João Pacheco; ROCHA, Carlos Augusto (Org.). A presença indígena na formação do Brasil. Brasília: Ministério da Educação/LACED/Museu Nacional, 2006.

OLIVEIRA, Ariovaldo Umbelino. A longa marcha do campesinato brasileiro: movimentos sociais, conflitos e reforma agrária. Estudos Avançados. v. 15, n. 43, p. 185-206, 2001.

PATNAIK, Utsa; PATNAIK, Prabhat. A theory of imperialism. New York: Columbia University Press, 2016.

PEET, Richard; HARTWICK, Elaine. Theories of development: contentions, arguments, alternatives. New York/London: The Guilford Press, 2015.

PEREIRA, Levi Marques. Os Terena de Buriti: as formas organizacionais, territorialização da identidade étnica. Dourados: UFGD, 2009.

PERES, Julie Stefane Dorrico. Literatura indígena e seus intelectuais no Brasil: da autoafirmação e da autoexpressão como minoria à resistência e à luta político-culturais. Revista de Estudos e Pesquisas sobre as Américas, Brasília, v. 11, n. 3, p. 114-36, 2017.

POLANYI, Karl. The great transformation: the political and economic origins of our time. Boston: Beacon Press, 2001.

PRASHAD, Vijay. The poorer nations: a possible history of the global south. London/New York: Verso, 2012.

RIST, Gilbert. The story of development: from western origins to global faith. London/ New York: Zed Books, 2014.

RIST, Gilbert. Development as a buzzword. Development in Practice, [s.I.], v. 17, n. 4, p. 485-91, 2007.

RIST, Gilbert. Le développément: histoire d'une croyance occidentale. Paris: Presses de Science Po, 2001.

ROSA, Hartmut. Social acceleration: a new theory of modernity. New York: Columbia University Press, 2013.

SANTOS, Milton. A urbanização brasileira. São Paulo: EDUSP, 2009. 
SEBASTIÃO, Lindomar Lili. A diáspora Guaná (Terena) no pós-guerra da tríplice aliança e os reflexos em seus territórios no Estado de Mato Grosso do Sul. Tellus, Campo Grande, n. 30, p. 89-110, jan./jun. 2016.

SEVERO, Cristine Gorski. A invenção colonial das línguas da américa. Alfa, São Paulo, v. 60, n. 1, p. 11-28, 2016.

SHIVA, Vandana. Biopiracy: the plunder of nature and knowledge. Berkeley: Atlantic Books, 2016.

SILVA, Elizângela Cardoso de Araújo. Povos indígenas e o direito à terra na realidade brasileira. Serviço Social \& Sociedade, São Paulo. n. 133, p. 480-500, set./dez. 2018.

SIQUEIRA JUNIOR, Jaime. A experiência do Projeto GATI em terras indígenas. Brasília: IEB, 2016.

SIQUEIRA, Lucília. O nascimento da américa portuguesa no contexto imperial lusitano: considerações teóricas a partir das diferenças entre a historiografia recente e o ensino de história. História, São Paulo, v. 28, n. 1, p. 99-125, 2009. Disponível em https://www. scielo.br/pdf/his/v28n1/04.pdf. Acesso em: 23 nov. 2020.

SOUZA LIMA, Antonio Carlos. Um olhar sobre a presença das populações nativas na invenção do Brasil. In: LOPES DA SILVA, Aracy; GRUPIONI, Luis Donizeti Benzi (Org.). A Temática Indígena na Escola. Brasília: MEC/MARI/UNESCO, 1995.

TEDESCO, João Carlos; SEMINOTTI, Jonas José; ROCHA, Humberto José (Org.). Movimentos e lutas sociais pela terra no sul do Brasil: questões contemporâneas. Chapecó: UFFS, 2018.

VARGAS, Vera Lúcia Ferreira. A dimensão sociopolítica do território para os Terena: as aldeias nos séculos XX e XXI. 188 f. 2011. Tese (Doutorado em História) - Universidade Federal Fluminense, Rio de Janeiro, RJ, 2011.

VIVEIROS DE CASTRO, Eduardo. Metafísicas Canibais. São Paulo: Cosac Naify, 2015.

\section{Sobre os autores:}

Josemar de Campos Maciel: Pós-doutor em Estudos Culturais pela Universidade de São Paulo/USP. Doutor em Psicologia pela Pontifícia Universidade Católica de Campinas (PUCCAMP). Mestre em Psicologia pela Universidade Católica Dom Bosco (UCDB) e em Teologia Sistemática pela Pontificia Universidade Gregoriana de Roma (PUG). Graduado em Filosofia pelas Faculdades Unidas Católicas do Mato Grosso (FUCMAT) e em Teologia pela PUG, de Roma. Atualmente, é professor na 
UCDB: Mestrado em Desenvolvimento Local. E-mail: rf5033@ucdb.br, ORCID: https://orcid.org/0000-0001-8277-9422

Levi Marques Pereira: Pós-doutor em Antropologia Social pela Universidade Estadual de Campinas (UNICAMP) e em Antropologia Social pela Universidade de São Paulo (USP). Doutor em Ciências, na área de Antropologia Social, pela USP. Mestre em Antropologia Social pela UNICAMP. Especialista em História da América Latina pela Universidade Federal de Mato Grosso do Sul (UFMS). Graduado e licenciado em Ciências Sociais pela Pontifícia Universidade Católica de Campinas (PUCCAMP). Atualmente é professor associado na Universidade Federal da Grande Dourados (UFGD), onde leciona na Faculdade Intercultural Indígena (Licenciatura Intercultural Indígena- Teko Arandu) e participa dos programas de pós-graduação em Antropologia e História. E-mail: levimarquespereira2@gmail.com, ORCID: https://orcid.org/0000-0002-8513-2613

Yan Leite Chaparro: Pós-doutor em Antropologia Social pela Universidade Federal da Grande Dourados (UFGD). Doutor em Desenvolvimento Local pela Universidade Católica Dom Bosco (UCDB). Mestre em Desenvolvimento Local pela UCDB. Graduado em Psicologia pela UCDB. Integrante do Grupo de Pesquisa Estudos Críticos do Desenvolvimento/CNPq, do Laboratório de Humanidades/Labuh e da rede OuVir Psicologia e Povos da Terra. E-mail: yanchaparro@gmail.com, ORCID: http://orcid.org/0000-0002-7058-2988

Recebido em: 06/12/2020.

Aprovado para publicação em: 16/12/2020. 